\title{
Cervical opening in relation to progesterone and oestradiol during heat in beagle bitches
}

\author{
L. D. M. Silva, K. Onclin and J. P. Verstegen* \\ Department of Small Animal Reproduction, Veterinary College, University of Liège, Bd. de Colonster, \\ B. 44, 4000 - Liège, Belgium
}

\begin{abstract}
The relationship between hormonal profile and cervical opening and closure was analysed during heat in seven bitches. The bitches were studied each day from the beginning of pro-oestrus until 5 days after cytological metoestrus. Vaginography was performed using a radiopaque contrast dye injected through an insemination probe and blood samples were collected daily. The opening of the cervix was observed, in pro-oestrus, $2.6 \pm 2.8$ days before the $\mathrm{LH}$ peak. The progesterone and oestradiol values at that time were $2.0 \pm 2.4 \mathrm{nmol}^{-1}$ and $171.1 \pm 133.1 \mathrm{pmol}^{-1}$, respectively. The opening of the cervix was observed concurrent with the day of the maximal value of the oestradiol:progesterone ratio, just before the decline of oestrogen preceding the LH peak. Differences between the oestradiol:progesterone ratio the day before, the day of and the day after opening were significant. The closure of the cervix occurred $6.7 \pm 1.4$ days after the LH peak and $2.6 \pm 1$ days before the first sign of cytological metoestrus. The progesterone and oestradiol concentrations at that time were $68.9 \pm 15.4 \mathrm{nmol} \mathrm{l}^{-1}$ and $16 \pm 10.3 \mathrm{pmol} \mathrm{l}^{-1}$, respectively. All bitches were in cytological oestrus when the cervix closed. These data indicate that there is a relationship between hormonal profile and cervical opening and that breeding success may also be temporarily limited, not only by oestrous behaviour, but also by cervical closure. In the beagle colony studied, a blood concentration of $60 \mathrm{nmol}$ progesterone $\mathrm{l}^{-1}$ would give a good indication that no success will follow artificial vaginal insemination or natural mating.
\end{abstract}

\section{Introduction}

In many species, including dogs, the cervix is an important barrier and filter to all physiological and pathological processes related to fertilization and reproduction (Vaissaire, 1977). The physiological changes in the cervix during the canine oestrous cycle have never been studied, in spite of extensive information on the variation of the caudal reproductive tract of the bitch during the oestrous cycle (Lindsay, 1983).

In ewes, the cervix is completely impermeable to spermatozoa during anoestrus and partially impermeable during dioestrus (Vaissaire, 1977). In cattle, it is closed during dioestrus and pregnancy, but seems to be open during oestrus (Arthur et al., 1989; McDonald and Pineda, 1989). However, in ruminants, closure is only relative, since the barrier consists of an occlusion of thick mucus, the secretion of which has been stimulated by progesterone. Similarly, changes of cervical or vaginal mucus related to the oestrous cycle have been demonstrated in many species (Abusineina, 1962; Betteridge and Raeside, 1962; Noonan et al., 1975; Grobbelaar and Kay, 1985). In bitches, crystallization of the anterior vaginal fluid has also been described (England and Allen, 1989). However, the role of cervical fluid in the process of fertilization seems to be reduced,

${ }^{*}$ Correspondence.

Received 23 November 1994. as demonstrated by results after intrauterine insemination (Linde-Forsberg and Forsberg, 1993).

In bitches, the cervix is long and longitudinally occluded by epithelial folds and is covered by columnar epithelium (England, 1993). The cervical canal is oblique in a dorsoventral direction, with the external os in close apposition to the ventral area of the vaginal fornix (McDonald and Pineda, 1989). At oestrus, under the influence of oestrogen, a relaxation of the cervical folds is observed; this phenomenon is similar to that which occurs in mares and cows (Arthur et al., 1989; McDonald and Pineda, 1989).

Some hysterographic studies have been carried out to establish the normal radiographic appearance of the female canine genital system and the uterine outline in certain pathological conditions (Collery, 1956; Cobb, 1959; Allen and France, 1985; Lagerstedt and Obel, 1987; Lagerstedt, 1993). Two studies showed that the cervix is permeable to contrast medium at fixed times during pro-oestrus and oestrus (Linde, 1978) and during a variable period of 9-60 days after parturition or Caesarean section (Allen and France, 1985). Allen and France (1985) reported an open cervix as early as day 3 after the beginning of pro-oestrus and that the cervix remains patent until day 14 of the oestrous cycle, when the bitches are still in standing oestrus. However, they neither characterized kinetic variations in relation to the oestrous cycle nor analysed the relation between the cervical opening and hormonal profiles. 
The aims of this study were (i) to time the dynamics of cervix opening and closure in relation to the LH peak, and (ii) to determine whether there is a relationship between the hormonal profile and the cervical dynamics.

\section{Materials and Methods}

All experiments were carried out according to the Belgian regulations for animal research and experimentation.

\section{Animals}

Seven female Beagles, known to be reproductively normal from previous cycles and successful pregnancies, ranging in age from 2 to 6 years and weighing $12-14 \mathrm{~kg}$, were used. They were housed two per cage $(1.1 \mathrm{~m} \times 1.5 \mathrm{~m})$ and had access to exercise yards for $2 \mathrm{~h}$ per day. They were fed a commercial dry food (Purina: Pro Plan-Nutritional Excellence) once daily and had free access to water. They were examined each day during anoestrus to detect the beginning of pro-oestrus, as defined below.

The cycle stages were determined by clinical examination, hormonal profiles and vaginal cytology.

\section{Definitions}

The first day of pro-oestrus was defined as the first day of vulval swelling and detection of serosanguineous vaginal discharge. As mating may be observed as early as 4 days before the $\mathrm{LH}$ peak or as late as 6 days after the $\mathrm{LH}$ peak (Concannon, 1986) and pro-oestrus varies in duration and characteristics among animals, to allow comparison of results, we considered day 0 as the day of the estimated LH peak. The day of the LH peak was estimated as coincident with the day when progesterone concentrations, after a significant increase, reached values of $4.77-6.36 \mathrm{nmol} \mathrm{l}^{-1}$ (Concannon et al., 1977).

The duration of pro-oestrus was defined as the interval, in days, between the appearance of vulval swelling and vaginal bleeding (Concannon and DiGregorio, 1986) and day 0 . The duration of oestrus was defined as the interval, in days, between day 0 and the first day of cytological metoestrus. The duration of heat was defined as pro-oestrus duration plus oestrus duration. Cytological oestrus was characterized by anuclear superficial cells, high concentrations of superficial cells with picnotic nuclei and large intermediate cells (Schutte, 1967). The first day of cytological metoestrus was defined as the day on which parabasal and intermediate cells and numerous white blood cells reappeared in vaginal smears (Schutte, 1967).

\section{Clinical examinations and vaginal smears}

The bitches were observed every day for the presence of vulval swelling and serosanguineous vaginal discharge as indicators of the onset of pro-oestrus. Vaginal smears were taken daily during pro-oestrus and oestrus until the fifth day of metoestrus, and were stained with haematoxylin-eosin (Hemacolor: Merck, Darmstad). Smears were analysed according to Concannon and DiGregorio (1986).

\section{Blood samples and hormonal profiles}

Blood samples were collected by jugular venepuncture into heparinized tubes daily from the first day of pro-oestrus until metoestrus. Plasma was obtained after centrifugation of blood samples at $1000 \mathrm{~g}$ for $15 \mathrm{~min}$ and was stored at $-20^{\circ} \mathrm{C}$ until assayed for progesterone and oestradiol. Progesterone concentrations were measured by a commercial radioimmunoassay kit (Progesterone Coat-a-Count Kit: Diagnostic Products Corporation, Humbeek-Grimbergen), validated for dog plasma (Srikandakumar et al., 1986; Concannon et al., 1989). The sensitivity at $95 \%$ bound was $0.3 \mathrm{nmol} \mathrm{l}^{-1}$ and the intraand interassay coefficients of variation were 5.1 and $8.8 \%$, respectively. Concentrations of oestradiol were measured by a commercial double-antibody radioimmunoassay kit for human serum or plasma (Double Antibody Oestrogen Kit: Diagnostic Products Corporation), validated for dog plasma (Verstegen et al., 1994). The sensitivity at $95 \%$ bound was $9.5 \mathrm{pmol} \mathrm{I}^{-1}$ and the intra- and interassay coefficients of variation were 3.4 and $3.9 \%$, respectively.

\section{Vaginography}

Radiographic examinations were performed from the first day of pro-oestrus until 5 days after cytological metoestrus. A two-way flexible insemination probe 'Osiris' was used to inject and prevent backflow of the radiopaque fluid, containing natriumioxitalamat and negluminioxitalamat (Telebrix 38: Codali, Brussels) (Mialot et al., 1985). It was introduced into the cranial portion of the vagina and the balloon was insufflated with $20-40 \mathrm{ml}$ of air. A variable amount of contrast medium $(20-60 \mathrm{ml})$, sufficient to fill the vagina and uterus, was injected and the images were monitored for at least $10 \mathrm{~min}$ by fluoroscopy. When the cervix was open, the radiopaque fluid could be seen entering the uterine body and both uterine horns. Radiographic exposures were made as required.

\section{Statistical analysis}

The data were analysed using descriptive analysis on a Macintosh computer (Apple) using the STATVIEW 4.02 program. The oestradiol:progesterone ratios were compared by using the paired Student's $t$ test. Analyses were considered significant when $P<0.05$ (Lentner, 1982).

\section{Results}

Individual and pooled hormonal data and data on kinetic changes in cervical opening are presented (Fig. 1).

The animals had normal oestrous cycles with a mean duration of heat of $17.2 \pm 1.7$ days (median 17, range 15-19). Mean durations of pro-oestrus and oestrus were $7.9 \pm 2.1$ (median 8, range 5-11) and $9.3 \pm 1$ days (median 9, range 8-11), respectively. Mean progesterone values at the $\mathrm{LH}$ peak were $4.9 \pm 0.6 \mathrm{nmol}^{-1}$ (median 4.8, range 3.1-6) and $82.7 \pm 29.6 \mathrm{nmol} \mathrm{l}^{-1}$ (median 76.4, range 43.6-127.2) at the first day of cytological metoestrus.

At the first day of pro-oestrus, the cervix was closed and, even if a large volume of contrast medium was injected, no 

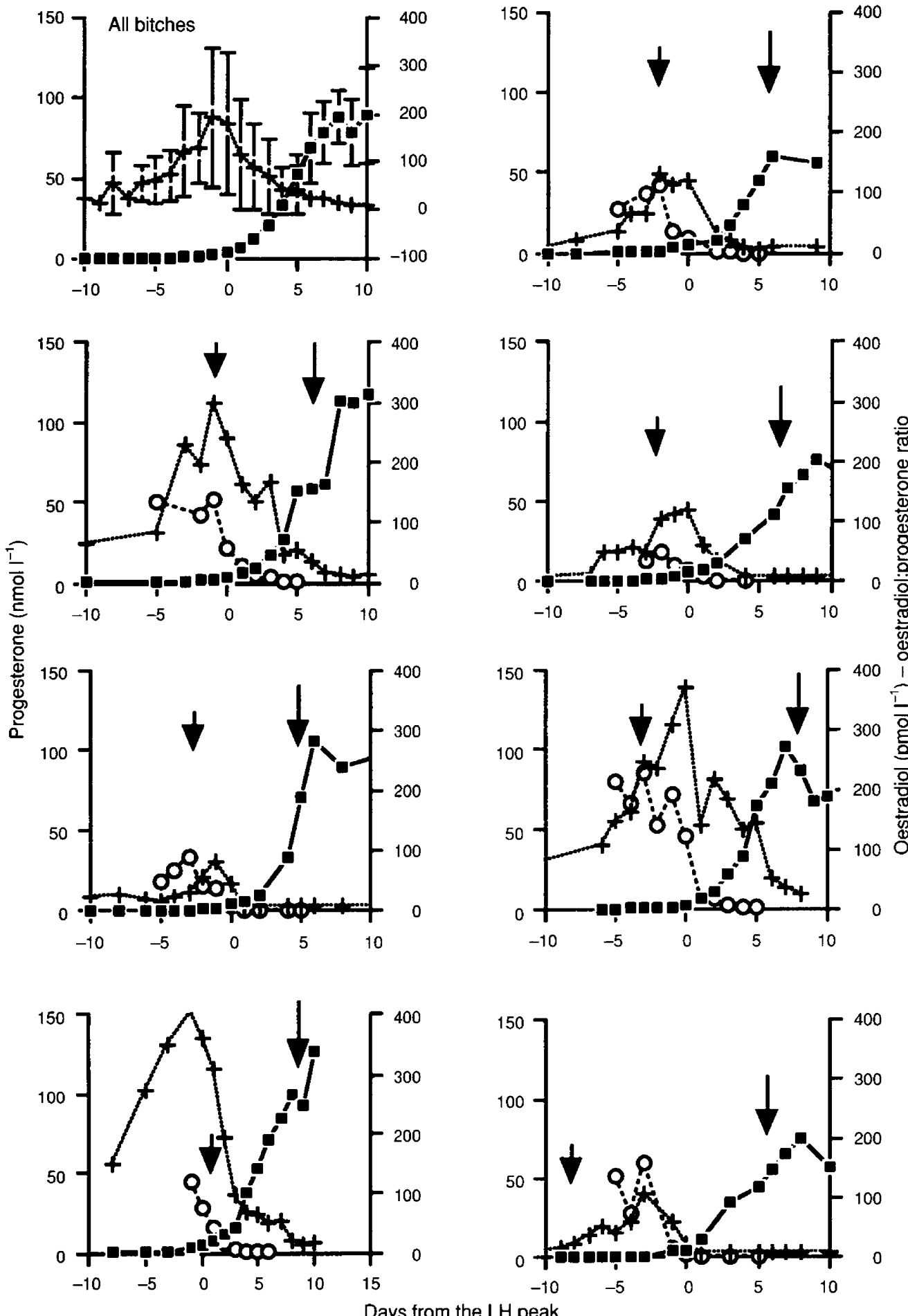

Fig. 1. Mean \pm SD hormonal profile for all bitches. Individual hormone profiles and oestradiol:progesterone ratio for each bitch. $(\boldsymbol{D})$ progesterone, $(+)$ oestradiol, $(O)$ oestradiol:progesterone ratio. Short arrow: day of opening; long arrow: day of closure of the cervix. It can be observed that opening of the cervix occurred in five out of seven bitches on the day of maximal oestradiol:progesterone ratio, when oestradiol concentrations were high and progesterone concentrations were basal. However, in one bitch the cervix opened 8 days before the estimated LH peak, when oestradiol was at a low concentration and, in another bitch the cervix opened at 1 day after the estimated LH peak, when progesterone concentration was higher than basal. At the closure of the cervix, all bitches had high progesterone concentrations and basal oestradiol concentrations. 

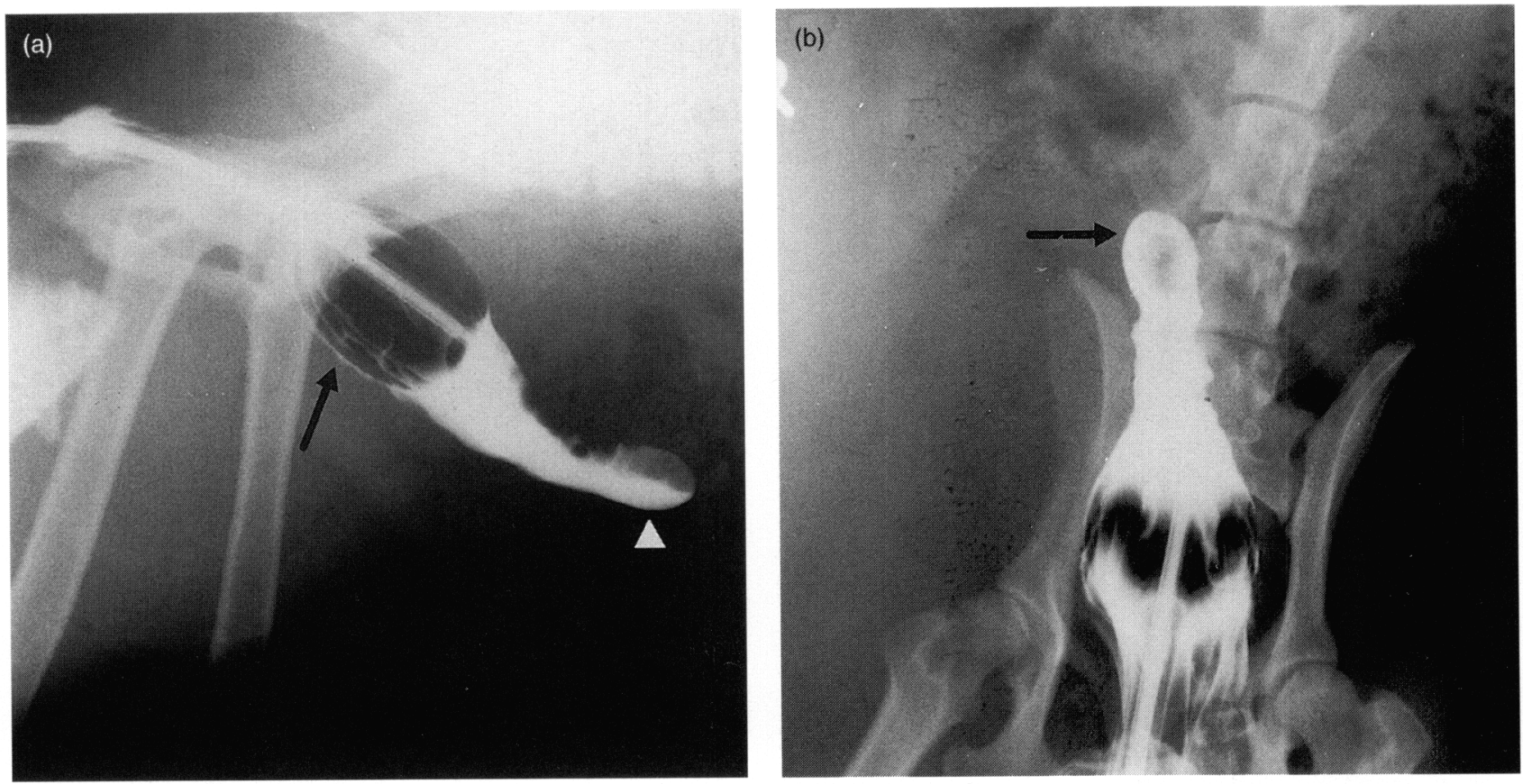

Fig. 2. (a) Radiographic lateral view of the closed canine cervix. The typical spoon shape of the cervix can be observed (white triangle). No contrast medium can pass through the cervix, and accumulate in the cranial vagina. The balloon of the 'Osiris' probe can be seen in the vagina (black arrow), impeaching a contrast reflux. (b) Radiographic ventro-dorsal view of the closed cervix (black arrow). As in (a), no contrast medium is seen entering the uterus.

fluid passed through the cervix into the uterine body. During that time, the typical spoon shape of the cervix was observed (Fig. 2). At the opening of the cervix, the contrast medium could be seen in the uterine horns (Fig. 3).

The opening of the cervix occurred $2.6 \pm 2.8$ days (mean $\pm \mathrm{SD}$ ) before the $\mathrm{LH}$ peak (median -2 , range -8 to +1 ) and $11.9 \pm 2.6$ days before day 1 of cytological metoestrus (median 11, range 9-16). At that time, six of the seven bitches presented vaginal smears of pro-oestrus and progesterone concentrations of $1.2 \pm 0.8 \mathrm{nmol} 1^{-1}$, median 1.1, range $0.3-$ 2.2. However, one bitch had an oestrous smear and a progesterone concentration of $7.2 \mathrm{nmol}^{-1}$ (Fig. 1). The plasma concentrations of oestradiol were $171.1 \pm 133.1 \mathrm{pmol} \mathrm{I}^{-1}$ (median 131.5, range 24.1-362.2) and were close to the maximum values observed in each animal except one. In this animal, the opening of the cervix was observed 8 days before the LH peak, when oestradiol value was close to basal values.

The oestradiol:progesterone ratio progressively increased in pro-oestrus and suddenly decreased close to oestrus $(87.7 \pm 47.9,106.7 \pm 61.4$ and $63.6 \pm 49$, the day before, the day of and the day after the opening of the cervix, respectively). There were no significant differences in the oestradiol: progesterone ratios among these 3 days $(P>0.05)$, when all animals were taken into account (Fig. 4). However, two animals presented a different pattern of opening; one presented the opening 8 days before and the other 1 day after the $\mathrm{LH}$ peak. If the data of these two outlier bitches are removed, the differences become significant $(P<0.05), 97.6 \pm 54$, $124.7 \pm 63.7$ and $60.4 \pm 45.1$, respectively (Fig. 4 ).

The closure of the cervix, characterized by the blockade of contrast medium in the vagina, occurred $6.7 \pm 1.4$ days (mean $\pm \mathrm{SD}$ ) after the LH peak (median 6, range 5-9). At that time, all the bitches had vaginal smears characteristic of oestrus, the plasma progesterone concentrations were $68.9 \pm$ $15.4 \mathrm{nmol} \mathrm{l}^{-1}$ (median 59.9, range 54.9-93.2) and the plasma concentrations of oestradiol were $16 \pm 10.3 \mathrm{pmol} \mathrm{l}^{-1}$ (median 9.5, range 9.5-35.9). The mean time ( $\pm \mathrm{SD})$ from the closure of the cervix to day 1 of metoestrus was $2.6 \pm 1$ (median 3, range 1-4) days. The interval between the opening and closing of the cervix was $9.3 \pm 2.4$ days (median 8 , range $7-14$ ).

\section{Discussion}

The study reported here presents the first description of cervical dynamics during pro-oestrus and oestrus in relation to the hormonal profile in bitches. To analyse these changes, we defined day 0 as the day on which progesterone reached 4.77-6.36 nmol $\mathrm{l}^{-1}$, corresponding to the day of the LH peak (Concannon et al., 1977). The LH peak is the best reference to use to standardize comparisons between animals and to eliminate variations between bitches. Vaginal cytology, because of large variations between bitches (Tsutsui, 1975), was not used for reference, but merely to indicate the characteristics of the stage of the oestrous cycle each bitch was at.

The oestrous cycles and the progesterone and oestradiol profiles of the bitches were normal (Chakraborty, 1987; Verstegen et al., 1994), allowing us to use these animals as models of our beagle population.

A variable volume of contrast medium (range $20-60 \mathrm{ml}$ ) was injected through the insemination probe to fill the vagina and the uterus. Holt et al. (1984) showed that approximately $1 \mathrm{ml}$ of contrast medium $\mathrm{kg}^{-1}$ body mass is needed to fill the vagina, but under the influence of sex hormones, the required doses 

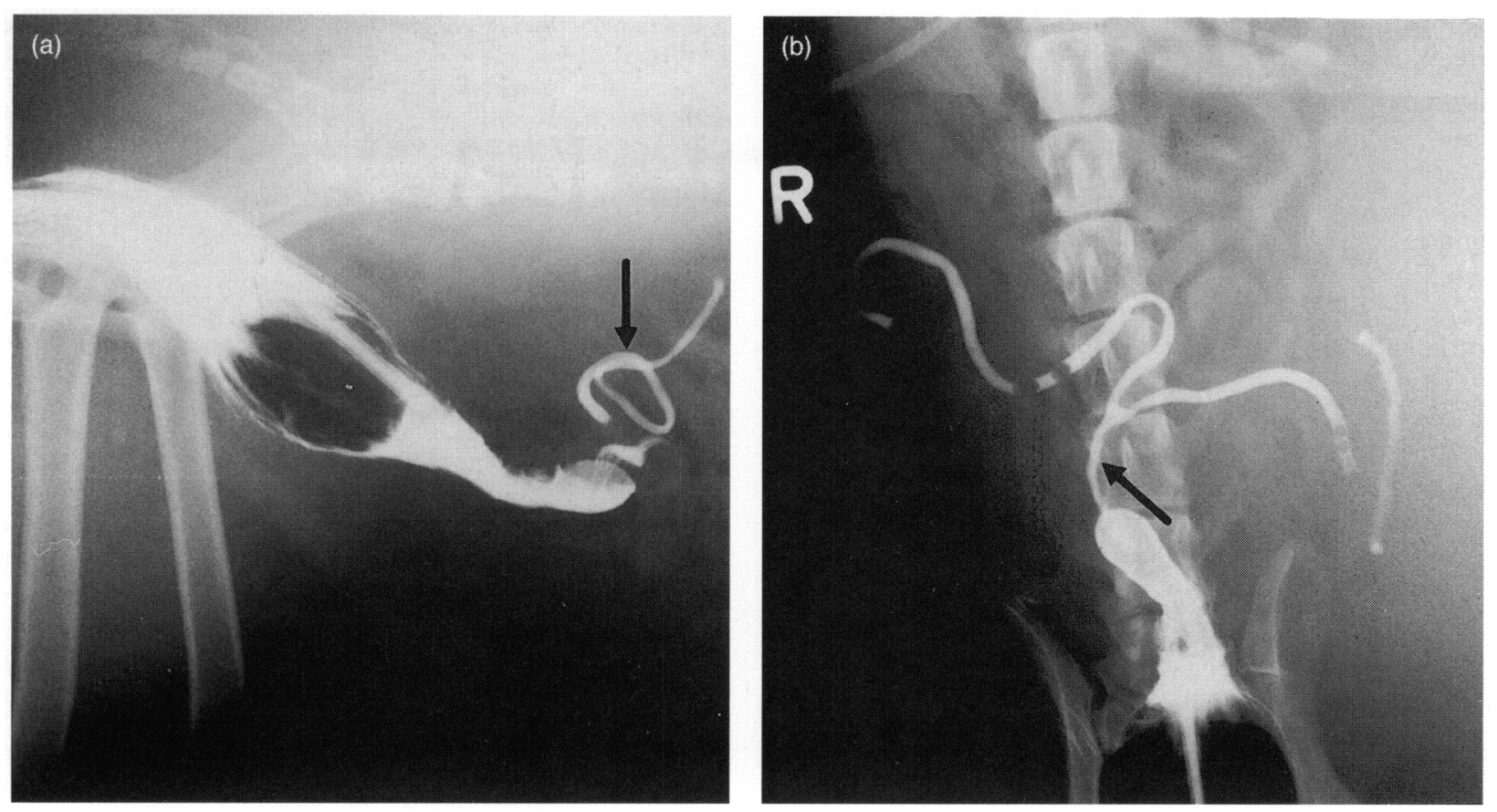

Fig. 3. (a) Radiographic lateral view of the opened cervix. The contrast medium can be seen in the cranial vagina and the uterus (arrow). (b) Radiographic ventro-dorsal view of the opened cervix. The contrast medium can be seen in the uterine body (arrow) and both uterine horns. Black images into the uterine horns correspond to air bubbles.

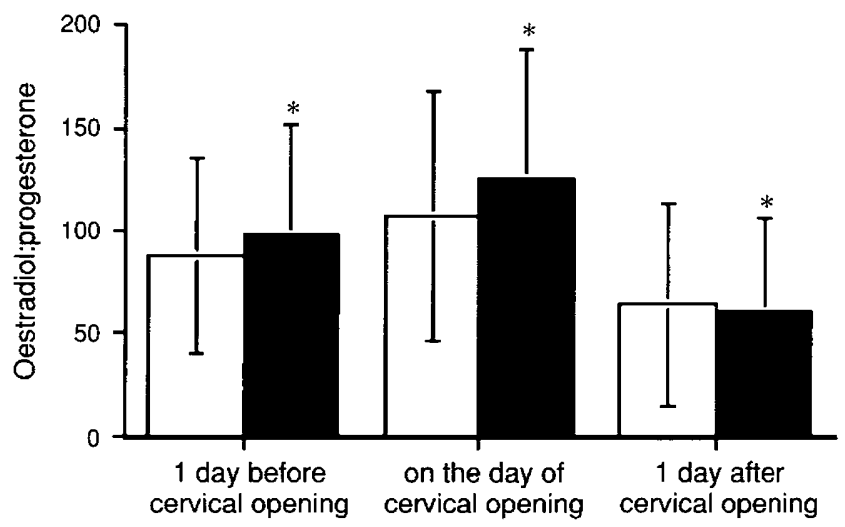

Fig. 4. Oestradiol:progesterone ratio on the days before, of and after the opening of the cervix. ( $\square$ ): seven bitches; $(\square)$ : five bitches. *Significant difference, Student's $t$ test $(P<0.05)$.

vary considerably. This may be due to the large vaginal relaxation observed during oestrus and the permeability of the cervix. The vaginography technique used here is similar to those used by Allen and France (1985), but was superior in that the balloon of the 'Osiris' probe prevented the reflux of contrast medium even when the cervix was closed.

In bitches, a rise in oestrogen, reaching peak values $0-2$ days before the preovulatory surge of LH is followed by a sharp decline, with values returning to basal after a few days (Concannon et al., 1975; Chakraborty, 1987). Coincident with the decrease in oestrogen, there is a progressive increase in progesterone concentration (Concannon et al., 1975; Chakraborty, 1987). In the study reported here, the opening of the cervix was coincident with the initiation of the decline in the oestrogen:progesterone ratio. However, some individual variations were observed. In six of seven animals, cervical opening was detected when the oestradiol concentration was close to its maximum, but in one bitch the cervix opened 8 days before the LH peak, when oestradiol and progesterone concentrations were still basal. This is probably related to the large variation in cyclic activity. The opening of the cervix 2 days before the LH peak may be related to the transition from pro-oestrous to oestrous behaviour that occurs, in general, within I day of the LH peak (Concannon, 1986). It would be interesting to establish whether the variation in the time of the opening of the cervix was related to mating behaviour.

The opening of the cervix was usually observed on the day of maximal oestradiol:progesterone ratio, before the sudden decrease in this parameter. This rapid fall occurs when follicles reach maturity, and is crucial to the occurrence of the preovulatory LH surge (Concannon et al., 1977, 1989).

The time of closure of the cervix varied little among the animals, occurring during oestrus an average of $6.7 \pm 1.4$ days after the LH peak (median 6, range 5-9) and $2.6 \pm 1$ days before cytological metoestrus (median 3, range 1-4). At that time, all the bitches had high concentrations of progesterone (68.9 $\pm 15.4 \mathrm{nmol} \mathrm{l}^{-1}$, median 59.9, range 54.9-93.2). Oestradiol was basal with mean values of $16.0 \pm 10.3 \mathrm{pmol}^{-1}$ (median 9.5, range 9.5-35.9). The time the cervix remained open was variable between bitches, with a mean of $9.3 \pm 2.4$ (median 8 , range $7-14$ ). The reason for this variation is not known.

The early closure of the cervix during oestrus is important for successful fertilization. Indeed, ovulation occurs between 38 and $44 \mathrm{~h}$ after the $\mathrm{LH}$ peak, and oocytes reach maturity about $48 \mathrm{~h}$ later (Concannon et al., 1977). Furthermore, Tsutsui (1989) 
reported that canine oocytes can be fertilized between 108 and $156 \mathrm{~h}$ after the $\mathrm{LH}$ peak. The time of closing of the cervix corresponds to the end of this fertilization period, 4.5-6.5 days after the LH peak. The data reported here indicate that the apparent reduction in oocyte life span observed in clinical studies (Tsutsui, 1989) may be due to closure of the cervix, rather than to reduction of oocyte survivability. The canine oocyte may remain fertile for a longer period, but, because the cervix is closed, fertilization after natural mating or vaginal insemination is no longer possible.

In conclusion, the cervix usually opens about 2 days before the LH peak, a period close to the time of first acceptance of the male. This opening is induced by the oestradiol:progesterone ratio approaching its maximal value and declining sharply one day later. Closure of the cervix occurs about 6 days after the LH peak, 3 days before the end of oestrus. The closure occurs when progesterone values are about $60 \mathrm{nmol} 1^{-1}$. This value may be of clinical importance for the estimation of the time after which vaginal insemination or natural mating will not result in fertilization.

The authors thank F. Leroy for radiographic technical assistance and M. Warnier for hormonal analyses. The authors also thank Purina for animals' food supply. L. D. M. Silva was supported by grants from CAPES.

\section{References}

Abusineina ME (1962) A study of the fern-like crystalline patterns of the cervical and vaginal mucus of cattle Veterinary Record 74 619-621

Allen WE and France C (1985) A contrast radiography study of the vagina and uterus of the normal bitch Journal of Small Animal Practice 26 153-166

Arthur GH, Noakes DE and Pearson H (Eds) (1989) The oestrous cycle and its contol. In Veferinary Reproduction and Obstetrics pp 13-16 (6th Edn). WB Saunders Co, Philadelphia

Betteridge KJ and Raeside JI (1962) Investigation of cervical mucus as indicator of ovarian activity in pigs Joumal of Reproduction and Fertility 3 410-421

Chakraborty PK (1987) Reproductive hormone concentrations during estrus, pregnancy, and pseudopregnancy in the Labrador bitch Theriogenology 27 $827-841$

Cobb LM (1959) The radiography outline of the genital system of the bitch Veterinary Record 71 66-68

Collery L (1956) Contrast hysterography in the bitch Irish Veterinary Journal 10 99-101

Concannon PW (1986) Canine pregnancy and parturition Veterinary Clinics of North America: Small Animal Practice 16 453-475

Concannon PW and DiGregorio GB (1986) Canine vaginal cytology. In Small Animal Reproduction and Infertility pp 96-111 (2nd Edn) Ed. TJ Burke. Lea \& Fabiger, Philadelphia

Concannon PW, Hansel W and Visek WJ (1975) The ovarian cycle of the bitch plasma estrogen, LH and progesterone Biology of Reproduction 13 112-121
Concannon PW, Hansel W and McEntee K (1977) Changes in LH, progesterone and sexual behavior associated with preovulatory luteinization in the bitch Biology of Reproduction 17 604-613

Concannon PW, McCann JP and Temple M (1989) Biology and endocrinology of ovulation, pregnancy and parturition in the dog Journal of Reproduction and Fertility Supplement 39 3-25

England GCW (1993) Quantitative study of cervical epithelial glandular tissue in the bitch Journal of Reproduction and Fertility Supplement 47551

England GCW and Allen WE (1989) Crystallization patterns in anterior vaginal fluid from bitches in oestrus Journal of Reproduction and Fertility 86 335-339

Grobbelaar JAN and Kay GW (1985) Cervical mucous scoring - a simple technique for the detection of oestrus in individually housed cattle Animal Technology 36 131-135

Holt PE, Gibbs C and Latham J (1984) An evaluation of positive contrast vagino-urethrography as a diagnostic aid in the bitch Journal of Small Animal Practice 25 531-549

Hopkins SM (1989) Reproductive patterns of cattle. In Veterinary Endocrinology and Reproduction pp 399-415 Ed. LE McDonald. Lea \& Fabiger, Philadelphia

Lagerstedt A-S (1993) Hysterography as a diagnostic aid in the bitch Journal of Reproduction and Fertility Supplement 47539

Lagerstedt A-S and Obel N (1987) Uterine cannulation in the bitch Journal of Veterinary Medical Association 34 90-101

Lentner C (1982) Statistical significance tests. In Geigy Scientific Tables pp 192-202 (8th Edn). Ciba Geigy Limited, Basle

Linde C (1978) Transport of radiopaque fluid into the uterus after vaginal deposition in the oestrous bitch Acta Veterinaria Scandinavica $19463-465$

Linde-Forsberg C and Forsberg M (1993) Results of 527 controlled artificial inseminations in dogs Journal of Reproduction and Fertility Supplement 47 313-323

Lindsay FEF (1983) The normal endoscopic appearance of the caudal reproductive tract of the cyclic and non-cyclic bitch: post-uterine endoscopy Journal of Small Animal Practice 24 1-15

Mialot JP, Dumon C and Cassou B (1985) Insémination artificielle chez la chienne: mise en place de semence fraîche avec le pistolet souple 'Osiris' Pratique Médicale et Chirurgicale de l'Animal de Compagnie 20 213-220

Noonan JJ, Schultze AB and Ellington EF (1975) Changes in bovine cervical and vaginal mucus during the estrous cycle and early pregnancy Journal of Animal Science 41 1084-1089

Schutte AP (1967) Canine vaginal cytology. II Cyclic changes Joumal of Small Animal Practice 8 307-311

Srikandakumar A, Ingraham RH, Ellsworth M, Archbald LF, Liao A and Godke RA (1986) Comparison of a solid phase, no-extraction radioimmunoassay for progesterone with an extraction assay for monitoring luteal function in the mare, bitch and cow Theriogenology 26 779-793

Tsutsui T (1975) Studies on the physiology of reproduction in the dog. III observation of vaginal smear in estrus cycle Japanese Journal of Animal Reproduction 21 37-42

Tsutsui T (1989) Gamete physiology and timing of ovulation and fertilization in dogs Journal of Reproduction and Fertility Supplement 39 269-275

Vaissaire JP (Ed.) (1977) Activité sexuelle femelle: migration des gamètes dans les voies généitales femelles. In Sexualité et Reproduction des Mammifères Domestiques et de Laboratoire pp 312-324. Maloine SA, Paris

Verstegen JP, Onclin K, Silva LDM, Cheron T, Stavrakis S and Concannon PW (1994) Early termination of anestrus and induction of fertile estrus in dogs by the dopamine super-agonist cabergoline Proceedings of the 27th Annual Meeting of the Society for the Study of Reproduction, Biology of Reproduction 50 (Supplement 1) 410 